This item was submitted to Loughborough's Research Repository by the author.

Items in Figshare are protected by copyright, with all rights reserved, unless otherwise indicated.

\title{
Lesson study partnerships in initial teacher education
}

\section{PLEASE CITE THE PUBLISHED VERSION}

https://books.emeraldinsight.com/page/detail/Lesson-Study-in-Initial-Teacher-Education/?k=9781787567986

\section{PUBLISHER}

Emerald Publishing Limited

VERSION

AM (Accepted Manuscript)

\section{PUBLISHER STATEMENT}

This paper was accepted for publication in the book Lesson Study in Initial Teacher Education: Principles and Practices and the definitive published version is available at https://books.emeraldinsight.com/page/detail/Lesson-Study-in-Initial-Teacher-Education/?k=9781787567986.

\section{LICENCE}

CC BY-NC 4.0

\section{REPOSITORY RECORD}

Baldry, Fay, and Colin Foster. 2019. "Lesson Study Partnerships in Initial Teacher Education". figshare. https://hdl.handle.net/2134/37708. 


\title{
Lesson study partnerships in initial teacher education
}

\author{
Fay Baldry* and Colin Foster** \\ ${ }^{*}$ School of Education, University of Leicester \\ **Mathematics Education Centre, Loughborough University
}

fb128@le.ac.uk and c.foster@lboro.ac.uk

\begin{abstract}
This chapter considers ways in which lesson study may be introduced and sustained within the school-university partnerships that already exist within an initial teacher education (ITE) course. In particular, we describe the challenges and opportunities associated with ITE lesson study partnerships and ways in which lesson study can deepen and even transform the nature of the school-university partnership. We draw on third-generation Cultural-Historical Activity Theory (Engeström, 2001) to highlight preservice teachers' roles as 'boundary crossers' between the activity system of the university ITE course and the activity system of the school department in which they are placed. We argue that pre-service teachers, despite their inexperience as teachers, have an important opportunity to introduce the practices of lesson study that they are learning about into the schools in which they are placed. They are also able to promote approaches to lesson planning and observation that support the values of the course and thus, through mentor development, strengthen the school-university partnership more widely than the specific lesson studies carried out. We outline three models for productive ITE lesson-study partnerships, and argue that even a relatively small number of lesson-study events throughout the school year can establish the beginnings of a transformation in the school culture away from a performative focus on evaluating the teacher and towards a more productive focus on school students' learning. This, in turn, deepens the partnership between university and school by aligning both parties more closely around a shared focus on studying learning.
\end{abstract}

\section{Keywords}

Cultural-historical activity theory; initial teacher education; lesson study; pedagogy; performativity; school-university partnerships

\section{Introduction}

The increasing global interest in Japanese lesson study since the publication of The Teaching Gap (Stigler \& Hiebert, 1999) has led to its growing use in schools across many parts of the world (Fernandez \& Yoshida, 2012). Teacher educators responsible for initial teacher education (ITE) courses have also considered ways in which lesson study can enhance teacher preparation (e.g. Baldry \& Foster, 2019). Lesson study in ITE inevitably raises the issue of school-university partnerships, since ITE courses are generally structured around some kind of shared responsibility between universities and schools for preparing future teachers. Partnership is often reported to be a difficult aspect of ITE, because the interests of schools and universities are rarely completely aligned and different knowledge is brought to the process (Kruger, Davies, Eckersley, Newell, \& Cherednichenko, 2009). Universities may stress the importance of critical perspectives on teacher education, focusing on theory and the weighing of academic evidence. Schools may be more concerned with 'what works' in the short term and in finding practical ways to meet more immediate goals. Schools in England are currently 
subject to an intensive performativity culture (Ball, 2003, 2017), which prioritises measuring school and teacher performance and attaches great value to achieving particular high-stakes national metrics.

When lesson study is adopted or adapted in ITE, this almost always takes place within the context of existing school-university partnerships that support the processes of the ITE course. Lesson study becomes another request or requirement which schools have to meet, and this is likely to affect the nature of the existing partnership. In this chapter, we follow Wake, Swan and Foster (2016) in drawing on the theoretical tools of thirdgeneration Cultural-Historical Activity Theory (CHAT, see Engeström, 1987, 2001) to conceptualise the university ITE course and the school subject department as two distinct activity systems. We see partnership as relating to the interaction between these two systems. In particular, we view the pre-service teacher as a boundary crosser (Akkerman \& Bakker, 2011), straddling the two activity systems and manifesting different roles and responsibilities within each. We consequently draw attention to a particularly powerful role for the pre-service teacher in inducting the school into a productive lesson-study process and into ways of working that have the potential to support key values associated with the school-university partnership.

In the following sections, we explore how ITE lesson study may modify and even, in some cases, redefine the school-university partnership. Our research question is: In what ways can lesson study develop and sustain effective school-university ITE partnerships? We will first outline, from a CHAT perspective, a lens for looking at schooluniversity partnerships in England, highlighting the tensions that typically exist within them. Then we examine ways in which lesson study may develop and sustain these partnerships by strengthening and, on occasion, even redefining them. We draw particular attention to the role of the pre-service teacher as a 'boundary crosser'.

\section{A CHAT perspective on school-university partnerships in ITE}

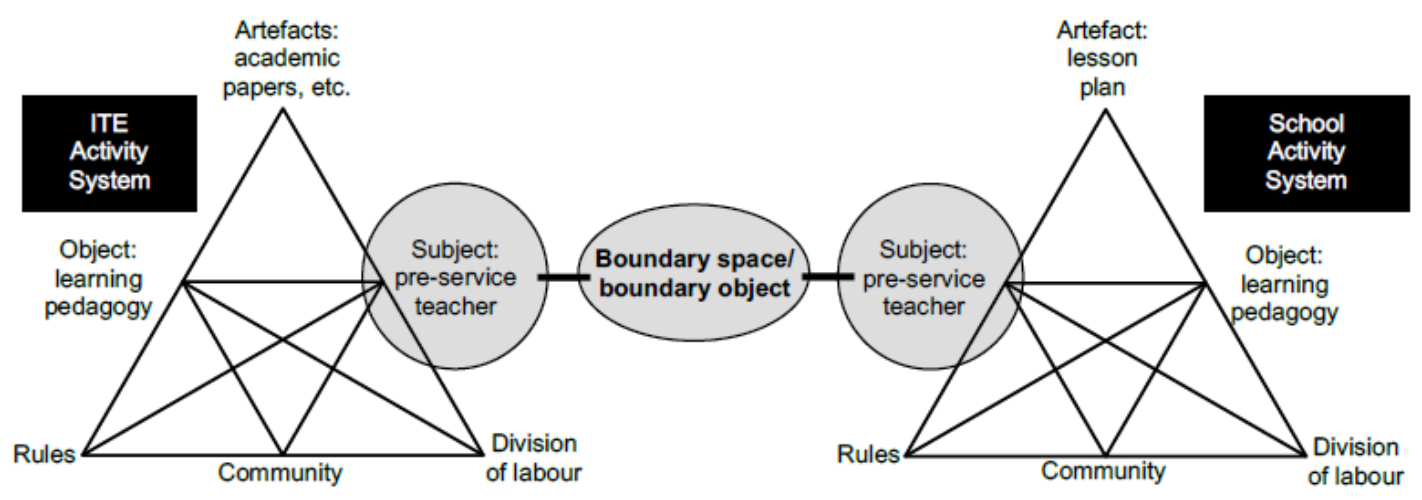

Figure 1. The boundary space between the two activity systems. Adapted from Wake, Swan \& Foster (2016)

We find it productive to conceive of the operation of lesson study in terms of culturalhistorical activity theory (CHAT, Engeström \& Cole, 1997; see Wake, Swan, \& Foster, 2016). An activity system captures the relationships between the participants within some unit as they work towards achieving particular objectives, mediated by various artefacts/tools. For our purposes in this chapter, focusing on school-university partnership, we are interested in two activity systems: 
(i) the ITE activity system, based in the university, in which the pre-service teacher is learning to become a teacher; and

(ii) the school activity system, mainly based around the school team (e.g., subject department at secondary level or year group at primary level) in which the preservice teacher is based.

As we outline below, we view the pre-service teacher as straddling these two activity systems - a member of both, but subject to different objects (goals), rules and responsibilities within each community (see Figure 1).

Apart from the pre-service teacher, the membership of the two activity systems is different. ${ }^{1}$ The objectives in both activity systems share some similarities - the preservice teacher is learning to become a teacher - but how this is enacted may be substantially different, with different emphases and expectations and differing perspectives on what this might mean and entail. Gaining certification is a dominant focus in both. Of course, in the activity system of the school, the principal objectives centre on the learning of the school students, rather than that of the pre-service teacher. In both activity systems, there is the additional mediating contributions of the community, with their divisions of labour and rules and norms. In activity system (i) this consists of the other pre-service teachers and the university tutors, together with the knowledge and values that they bring and emphasise; in activity system (ii) this consists of the other teachers in the school department, together with their institutional practices, values, practitioner knowledge and expectations.

Third-generation Activity Theory (Engeström, 2001) focuses on the interaction between different activity systems, and that is our particular interest in this chapter. We find the theoretical tools of CHAT helpful in highlighting the particularly central role of the preservice teacher in the boundary zone between the two activity systems, creating a 'third space' in which learning can take place (Tsui \& Law, 2007). As Tsui and Law (2007) note, a boundary zone:

is characterized by alternative or competing discourses and positionings which afford opportunities for the transformation of conflicts and tensions into rich zones of learning. Very often, in the course of resolving contradictions, a more encompassing object or motive for the activity is constructed, resulting in a transformed activity system (p. 1290).

The preservice teacher inhabits this boundary zone, becoming a boundary object (Akkerman \& Bakker, 2011; Star \& Griesemer, 1989), something which acquires a different meaning in different activity systems.

Where lesson study forms part of the ITE experience, this is usually initiated by the university and may be tied to an assessment point through an assignment which the pre-service teacher is required to complete, in which they report on their experiences in conducting lesson study in the school. This may be introduced as a way of raising the status of lesson study in the eyes of the pre-service teacher and the school, as lesson study is a small part of the overall ITE programme. However, it has the potential to over-formalise and instrumentalise the lesson study process, as we reflect on below.

\footnotetext{
${ }^{1}$ Occasionally, two pre-service teachers in the same subject are placed in the same school, but this is not the dominant practice in our experience of ITE in England.
} 
In activity system (i), the preservice teacher is overwhelmingly positioned as a learner; however, in activity system (ii), they may be a relative expert on lesson study, for instance, having participated in university sessions introducing them to the relevant practices, which the teachers in the school, though experienced in other ways, may typically in England be unfamiliar with.

A CHAT perspective on the school-university partnership highlights the importance of the different school and university perspectives being brought together through the pre-service teachers as boundary crossers. Particularly significant learning is thought to take place at boundaries, and the value of the juxtaposition of contrasting perspectives is a central theme in broader discourse relating to school-university partnerships. For example, Zeichner (2010), in a US context, argues for "student teacher learning that take[s] advantage of multiple sources of expertise that can support high-quality teaching" (p. 95). It is the differing sources of expertise provided by school and university that are seen as particularly valuable. In an Australian context, Kruger et al. (2009) found that successful school-university partnerships depended on trust, mutuality and reciprocity between preservice teachers, school teachers and university teacher educators. They concluded that "successful partnerships bring the stakeholders together around personalised and localised interests in learning, and school student learning in particular" (p. 10).

Our theoretical perspective on school-university partnerships highlights the importance of the role of the pre-service teacher in linking the two activity systems. In the next section, we explore how lesson study can be a powerful vehicle for defining (or redefining) the central processes of planning, teaching, observing and reflecting in school practice, thus strengthening the opportunities for learning for both the preservice teacher and the school department. We outline how mentor development is intimately linked to development of the school-university partnership.

\section{Lesson study within ITE partnerships}

In Japan, pre-service teachers will observe several lesson studies during the course of their initial teacher education (ITE) (Cajkler \& Wood, 2016a; Fernandez \& Yoshida, 2012) and in some cases may themselves teach a research lesson. Whilst practices vary in Japan, almost all schools undertake lesson study and have done so for many decades (Chichibu, 2016), so pre-service teachers participating in lesson study do so within an extremely well-established framework. It was estimated that by 2014 some 10 percent of schools in England had been involved in some form of lesson study, with a prediction that this would double by 2016 (Dudley, 2014c); so, whilst participation in lesson study is growing in England, it is still a very long way from established practice. In a similar way, pre-service teacher participation in lesson study appears to be growing (Lamb \& Aldous, 2016), but, with decentralised ITE course provision, decisions to use lesson study reside with individual course leaders, so lesson-study experience is inevitably patchy.

In England, pre-service teachers who participate in lesson study typically do so in schools where they undertake their teaching placements but at the instigation of the HEI (Higher Education Institution). Several different models of lesson study have been adopted in ITE courses in England in recent years (Baldry \& Foster, 2019). The composition of the lesson-study team varies, with almost all combinations of university tutors, pre-service teachers and school-based mentors seen somewhere. The role and 
level of involvement of school-based staff and university tutors can range from facilitating the organisation of the project through to full membership of the lesson study team. A common feature across different models of lesson study is a cycle beginning with collaborative planning, followed by an observed research lesson and some form of post-lesson review. We have previously outlined a 5-step approach to lesson study, which we have found effective and achievable in supporting pre-service teachers' first experiences of lesson study (Baldry \& Foster, 2019; see Figure 2). We have argued that this structure can maximise the chances of a positive first experience of lesson study that may encourage pre-service teachers and schools to persevere with the approach.

Lesson study has the potential to address key features of the school-university partnership, thereby contributing to developing the experience of the pre-service teacher in their school practicum and strengthening the school-university partnership. We now consider four features of lesson study which seem to be particularly important in terms of their influence on the nature of the school-university partnership

\section{(a) Knowledgeable others}

In Japanese lesson study, a recognised educational expert (a 'knowledgeable other', KO) usually provides a final commentary at the end of the post-lesson discussion. This is considered fundamental to foregrounding potential pedagogical learning that transcends the particular research lesson (Takahashi \& McDougal, 2016). In Japan, with their long history of using lesson study, the process itself is well understood, so the KO is able to focus on pedagogy. In schools in England, where lesson study is generally relatively unfamiliar, the KO role presents additional difficulties. In some cases, in early experiences of lesson study, a KO might need to focus as much on inducting teachers into the lesson-study process as on specific pedagogical issues. In ITE lesson study, the KO role is likely to be taken by some combination of school-based mentor and university tutor; however, although these people may be recognised as having pedagogical subject-specific expertise, in England they are unlikely to be highly experienced (if at all) with lesson study, which presents challenges.

A university tutor might not participate directly in the lesson study, but often attempts to address the process aspect of the KO role through teaching the pre-service teachers in the university about the lesson-study cycle, offering practical suggestions about how to go about it and providing written support materials. Lesson study initiated by HEIs usually forms part of an assessed element of the ITE course, so even if the university tutor has not undertaken lesson study in a school context themselves, they are seen as the expert in terms of how lesson study should be undertaken because they are in control of how the assignment aspect will be assessed. Both tutor and mentor are generally perceived to have relevant pedagogical knowledge, although tutors may sometimes be perceived as being less closely in touch with classroom reality (Archer, 2016), meaning that the pre-service teacher may have to negotiate different perspectives, priorites and foci.

When school-based staff are involved in the lesson-study project team, we have found that emphasising the fact that most teachers in Japan engage in lesson study and that everybody expects to learn from the process has aided engagement with an unfamiliar process. In addition, this supported the drive to shift in focus away from observations being about making judgements of teachers' performance towards learning more about pedagogy. 


\section{(b) The objectives of lesson study}

In Japan, many schools run lesson-study programmes lasting one to two years, with overarching research themes that stretch across subject areas (Takahashi \& McDougal, 2016). In ITE lesson study in England, the goal is generally specific to a particular topic area across a single subject, although broader skills have occasionally been the focus (e.g., Wake et al., 2016). Mentors may suggest links to whole-school priorities and tutors may wish to see connections to academic literature, while the pre-service teacher themselves may wish to focus on their personal targets for professional development. It is often a challenge to maintain the focus on student learning with the level of specificity required to avoid merely re-criculating everyone's previous opinions. We have found that goals related to engagement are often articulated in the first instance, with learning at best discussed in general terms. The term 'learning challenge' was coined (Cajkler, Wood, Norton, \& Pedder, 2013) to draw participants' attention to the need to state their research question in terms of learning, but we have found that this was not usually sufficient by itself, at least initially. One key role that a KO can play is to highlight that the development of a research question is an iterative process and to support participants through repeated cycles of refinement.

\section{(c) Collaborative planning of the research lesson}

One key aspect of planning for a lesson-study research lesson that distinguishes this from other types of lesson planning is kyouzai kenkyuu. This is the in-depth study of curriculum materials and relevant educational research as part of an extended period of planning leading to a lesson plan sited within a coherent theoretical framework. Takahashi and McDougal (2016) argue that this key aspect of Japanese lesson study is often missing when lesson study has been adopted elsewhere, and there is some evidence that this is the case in England (Cajkler \& Wood, 2016a). While collaborative planning in schools is often encouraged, it still remains unusual for in-service teachers in England to collaboratively plan their lessons. Pre-service teachers should be supported in developing their lesson planning as an integral part of all ITE courses, and lesson study can provide a vehicle for developing collaborative planning in schools settings.

The university tutor is usually well placed to facilitate access to wider research; indeed, teachers are unlikely to have access to the full range of academic sources or the time necessary to source relevant items (Cajkler et al., 2013). Consequently, we have found it productive for university tutors to support pre-service teachers' exploration of research and resources alongside the collaborative planning undertaken by the actual lessonstudy team. One very helpful strategy to maintain the focus on the learning of students is to have clearly articulated anticipated student responses (Dudley, 2015; Wake et al., 2016), which can also form the basis of a productive observation strategy. As with the research question, it can take a number of iterations for teachers to move from the desired, correct student responses to detailing a range of likely responses that include potential errors and misconceptions.

\section{(d) Observing the research lesson}

Research lessons in Japan may be observed by anything from just the lesson-study team through to hundreds of outside visitors. For example, on some occasions all teachers in an elementary school may act as observers, which is facilitated by early school closure 
(Toshiya \& Toshiyuki, 2013). In England, observation within ITE contexts tends be restricted to the lesson-study team.

Lesson observations are a regular part of school practice in England, and pre-service teachers are regularly observed whilst on teaching placement, with the observer generally making judgments on their teaching at the end of the lesson and offering suggestions for improvement. Given this context, it can be difficult to shift attention to observation of students' learning rather than the teacher's performance (Archer, 2016). If the lesson study is being conducted by a pre-service teacher and observed by their school-based mentor, the apparent resemblance to typical lesson observations that the pair would regularly undertake can make the transition particularly difficult (Cajkler \& Wood, 2016b). One strategy is to focus observation on two or three case-study students (e.g. Dudley, 2014b; Murphy, Weinhardt, Wyness, \& Rolfe, 2017). Coaching is often required to help the observers to make notes at the level of detail required to make significant contributions to the post-lesson discussions (Forsythe \& Baldry, 2017). With specific guidance and modelling, we have found that pre-service teachers can move from writing general comments, such as "the students seemed engaged" to more specific descriptions of students' actions. University tutors have the opportunity to coach their pre-service teachers in advance in this form of detailed observation, and this may consequently be an expertise which pre-service teachers can bring into school lesson study (Archer, 2016).

Dudley (2014a), among others, advocates using an observation pro forma consisting of the lesson plan with anticipated student responses. This links the planning and the observation as a preparation for the post-lesson discussion. Although this can limit the quality of the observation if the lesson planning is poor, this allows all observers to structure their observations around a common framework with the potential to collect data that will enable the research question to be answered. If time permits, one further source of insights into student learning is the use of stimulated recall interviews with the case-study students (Cajkler et al., 2013). Although these can sometimes be problematic to arrange, asking students to discuss and explain work that they have done almost invariably provides a rich source of information for the observers.

\section{(e) Post-lesson discussion}

In Japan, the KO plays a central role in the post-lesson discussion, as mentioned above. In England, the often performative nature of most lesson observations can make it difficult to main the focus on student learning rather than evaluative judgments of teaching (Amador \& Weiland, 2015). However, specifying clear discussion parameters and providing opportunities to plan the structure of debrief sessions are approaches that have had some success (Forsythe \& Baldry, 2017). The quality of the discussion will to some extent be limited by the appropriateness and detailed nature of the observations that have been recorded, as well as by the quality of the lesson planning that took place beforehand (Larssen et al., 2018). Detailed lesson observation notes are helpful but not sufficient to facilitate productive discussions. Detailed observations provide the opportunity to build a shared description of particular episodes, which can then be interrogated in terms of student thinking. However, productive discussions can become derailed if they drift towards teacher evaluation or unsubstantiated claims about student thinking. Beneficial strategies include highlighting in advance that comments such as "they got on really well with their work" are less helpful, and having 'stop' protocols that anyone can enact if they perceive a drift. One useful prompt is to 
modify any comments about what students 'did not understand' to hypotheses about student thinking; this can refocus discussions framed using deficit models of student thinking back onto learning.

\section{(f) 'Re-teaching' the lesson}

The idea that lesson study involves repeated cycles in which research lessons are 'retaught' to a different class has had some traction in England (e.g., Dudley, 2014a), but this seems to generally be considered optional in Japan (Toshiya \& Toshiyuki, 2013). The notion of 're-teaching' can lead to an undesirable focus on 'perfecting' a lesson plan, to the detriment of learning something pedagogically (Takahashi \& McDougal, 2016, p. 515). In ITE contexts, lesson study is often a one-off experience, and the key consideration is how findings are articulated and acted on, rather than an additional research lesson. For the pre-service teacher, as mentioned above, there is often a requirement to write an assignment about the lesson study, which forms an assessed part of their course.

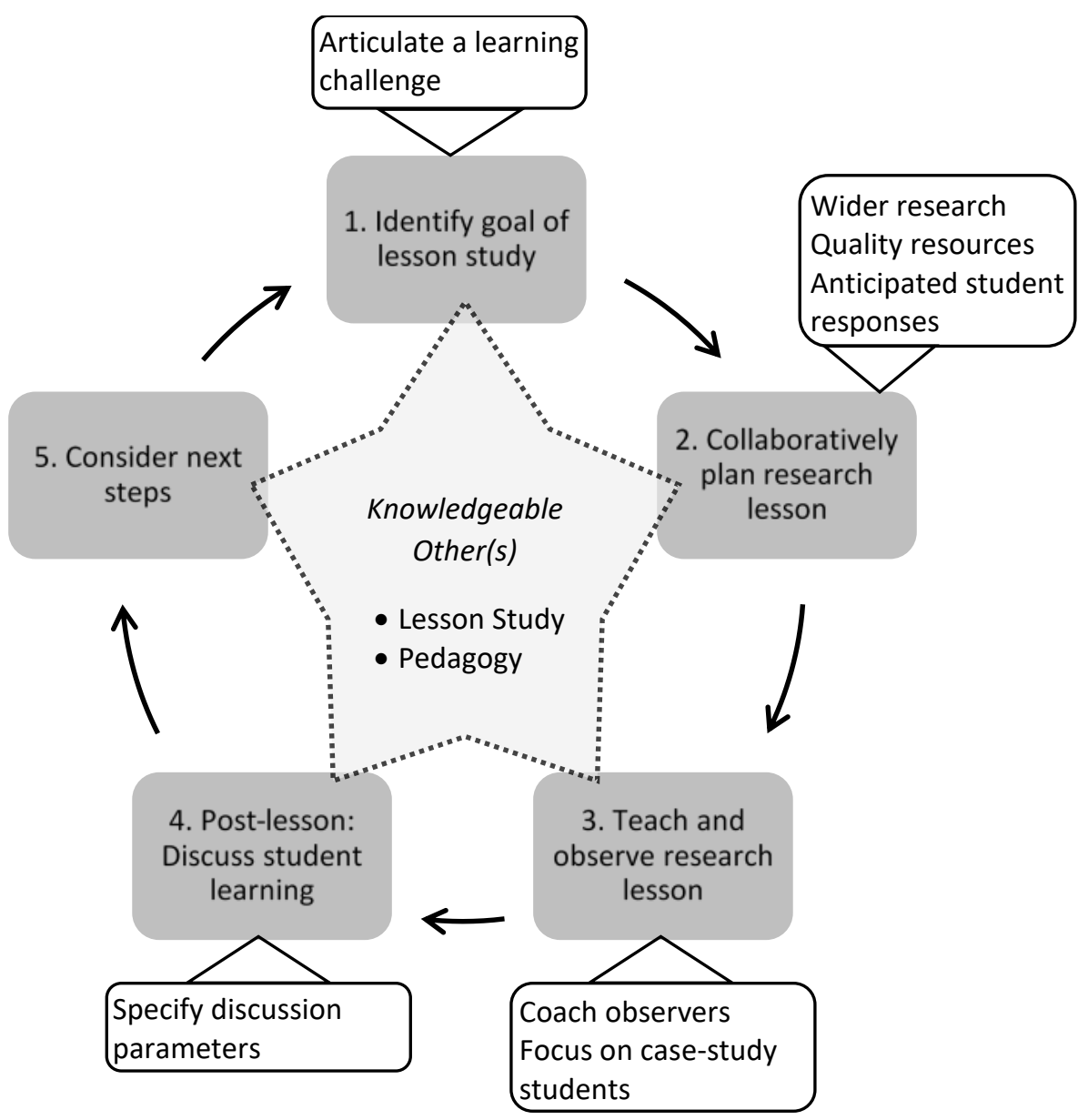

Figure 2. Key features of a lesson study for ITE (Adapted from Baldry \& Foster, 2019).

\section{Three examples of models of ITE lesson study in partnerships}

When considering how to implement lesson study within ITE, a number of different models have emerged. Here we consider three models in particular, with particular 
attention placed on the role lesson study can have on the partnership between HEIs and schools and on the pivotal role that pre-service teachers play as boundary crossers (see above) between the two activity systems.

\section{(a) Pre-service teacher lesson-study groups: University-led}

In the first few weeks of their PGCE course at the University of Leicester, secondary mathematics pre-service teachers, in teams of four, plan, teach and review three lessons over a three-week period; this is their first classroom experience on the course. The pre-service students are based at the university campus during this time, and the university tutor acts as a $\mathrm{KO}$ in relation to both pedagogy and the lesson-study process. This includes leading discussions on educational research, signposting resources, some joint observations and the structuring of post-lesson discussions (Forsythe \& Baldry, 2017). A local 16-18 further education college hosts the lesson study as part of an informal partnership, in which teachers at the college observe the lessons and sometimes offer informal comments, but are not involved further. The pre-service teachers have no direct contact with the college before first taught lesson; a university tutor accompanies them on this initial visit to facilitate introductions and to model observation strategies, but not in subsequent weeks.

We instigated this approach to lesson study to structure the pre-service teachers' first experiences in school and to introduce ideas relating to classroom-based research that they will need in order to carry out a research project later in their course. The collaborative planning of lesson study mitigates the inexperience of the pre-service teachers at this stage of the course and the project provides the college with an opportunity to work with the university, a relationship which both parties report that they value. During this project, the pre-service teachers are not only developing their understanding of both the university and the college, they are having their first experience of crossing between the ITE and 'school' (i.e., college) activity systems.

\section{(b) Pre-service teacher and school-based mentor dyad: University-led}

Pre-service teachers on our university-led routes spend 24 weeks on teaching placements, with their time split between two or three schools. The pre-service teachers undertake a small-scale classroom-based study as part of their masters-level assignments for the course. Within this established assignment framework, subsets of students have sometimes undertaken a lesson-study project at the instigation of their university tutor. These have generally been conducted by the pre-service teacher and their school-based mentor, with the mentor teaching one research lesson and the preservice teacher another. University tutors have acted as the KO in relation to the lessonstudy process, whereas both school-based mentors and university tutors are recognised as having pedagogical expertise, albeit in different forms. Mentors are directly involved in the planning of the research lesson and generally take the lead (Cajkler \& Wood, 2016a), whereas university tutors signpost relevant research and support the process at a distance.

Cajkler and Wood (2016b) reported on their work with two groups of pre-service teachers and school-based mentors. While there was some deviation from our expectations of lesson study, there was evidence that the process altered mentors' perspectives on their students' learning. Cajkler and Wood (2016b, p. 96) concluded that "lesson study offers an effective collaborative approach to facilitate transition into teaching"; however, lesson study has not yet been adopted across whole cohorts, and 
remains an ad hoc option, when sanctioned by university tutors. In this context, lesson study works within existing relationships, building the partnership by contributing to mentor development as well as supporting pre-service teachers' progress.

\section{(c) Pre-service teacher and school-based mentor dyad: School-led}

We also work with pre-service teachers on school-centred routes; in these cases, professional aspects of their course are the responsibility of the school consortia and the HEI responsibility is the master's level academic competencies. A similar lessonstudy programme has been established for 5 years, in which pre-service teachers work on a lesson-study project with their school-based mentors. In this model, university tutors have less contact with the pre-service teachers and only indirect contact with the school-based mentors. This necessitated the preparation of written protocols for the lesson study and the requirement for all pre-service teachers on this particular course to engage in lesson study. Analysis of the pre-service teachers' assignments indicates that the engagement of mentors varies considerably. Lesson observation pro formas indicated that some mentors and pre-service teachers had been able to make detailed observations of case-study students, but others contained comments about general engagement or the effectiveness of teaching, which is an approach that we had tried to discourage. However, in some cases, as a result of this initiative, schools have bought in to the lesson study approach and implemented it more widely within the subject department.

\section{Conclusion}

In this chapter, we have outlined three models for productive ITE lesson-study partnerships and highlighted ways in which lesson study may be introduced and sustained within them. Third-generation Cultural-Historical Activity Theory (Engeström, 2001) has enabled us to identify pre-service teachers' roles as boundary crossers between the activity systems of the university ITE course and the school subject department in which they are placed. We have argued that the pre-service teachers play a critical role in communicating ideas of lesson study introduced in university sessions into their schools. This means that, despite their relative inexperience as teachers, they have relevant knowledge that is of value to schools and which they can contribute to their subject departments. Further empicial work is needed to determine the ways in which this boundary crossing role supports the functioning of the university-school partnership.

Central to the partnership is an approach to observation and post-lesson discussion that focuses on student learning rather than on the teachers' performance. We recognise that this is considerably at odds with prevailing practices in the performativity culture that is so embedded in schools in England (Ball, 2003, 2107). Nevertheless, we have seen some indications that lesson study can be a powerful lever for mentor development, thereby strengthening the school-university partnership and having positive effects more widely in the student teachers' placement, well beyond the particular lesson study itself. Further research is needed to establish convincingly whether this is the case. However, in some cases, schools have been convinced of the value of lesson study and have adopted a version of lesson study more widely within their department as a result of first experiencing the process with their ITE pre-service teacher. 
Thus, we argue that even a small number of ITE lesson-studies carried out in schools can be the beginning of a transformation in the school culture of lesson observation away towards a productive focus on school students' learning. In this way, the schooluniversity partnership is deepened as it aligns more closely to the values that we seek to share.

\section{Acknowledgements}

We would like to thank the reviewer for very helpful comments on an earlier draft of this chapter and Professor Wasyl Cajkler for many insightful conversations.

\section{References}

Akkerman, S. F., \& Bakker, A. (2011). Boundary Crossing and Boundary Objects. Review of Educational Research, 81(2), 132-169.

Amador, J., \& Weiland, I. (2015). What preservice teachers and knowledgeable others professionally notice during lesson study. The Teacher Educator, 50(2), 109-126.

Archer, R. (2016). Lesson study in initial teacher education: students' positioning analysed through the lens of Figured Worlds. Paper presented at the British Society for Research into Learning Mathematics.

Baldry, F., \& Foster, C. (2019). Lesson Study in mathematics Initial Teacher Education in England. In R. Huang, A. Takahashi, \& P. da Ponte (Eds), Theory and Practice of Lesson Study in Mathematics: An International Perspective. Springer.

Ball, S. J. (2003). The teacher's soul and the terrors of performativity. Journal of Education Policy, 18(2), 215-228.

Ball, S. J. (2017). The Education Debate (3rd ed.). Bristol, UK: Policy Press.

Cajkler, W., \& Wood, P. (2016a). Adapting 'lesson study' to investigate classroom pedagogy in initial teacher education: what student-teachers think. Cambridge Journal of Education, 46(1), 1-18.

Cajkler, W., \& Wood, P. (2016b). Mentors and student-teachers "lesson studying" in initial teacher education. International Journal for Lesson and Learning Studies, 5(2), 84-98. doi:doi:10.1108/IJLLS-04-2015-0015

Cajkler, W., Wood, P., Norton, J., \& Pedder, D. (2013). Lesson Study: towards a collaborative approach to learning in Initial Teacher Education? Cambridge Journal of Education, 43(4), 537-554.

Chichibu, T. (2016). Impact on lesson study for initial teacher training in Japan: Focus on mentor roles and kyouzai-kenkyuu. International Journal for Lesson and Learning Studies, 5(2), 155-168. doi:doi:10.1108/IJLLS-01-2016-0001

Dudley, P. (2014a). How Lesson Study works and why it creates excellent learning and teaching. Lesson Study, 1.

Dudley, P. (2014b). Lesson Study Handbook (revised).

Dudley, P. (2014c). Lesson Study: Professional Learning for our time' a resume. Retrieved from http://lessonstudy.co.uk/2014/09/lesson-study-professionallearning-for-our-time

Dudley, P. (2015). Lesson Study: Professional learning for our time (1st ed. ed.). London: Taylor \& Francis Group.

Engeström, Y. (2001). Expansive Learning at Work: Toward an activity theoretical reconceptualization. Journal of Education and Work, 14(1), 133-156. doi:10.1080/13639080020028747 
Engeström, Y., \& Cole, M. (1997). Situated cognition in search of an agenda. In D. K. J. A. Whitson (Ed.), Situated cognition. Social, semiotic and psychological perspectives (pp. 301-309). Hillsdale, N.J.: Lawrence Erlbaum Associates.

Fernandez, C., \& Yoshida, M. (2012). Lesson study: A Japanese approach to improving mathematics teaching and learning: Routledge.

Forsythe, S., \& Baldry, F. (2017). Developing effective Learning Circles: An account of how student teachers participated in a shared dialogue of a team teaching experience. Paper presented at the European Conference on Educational Research 2017, Copenhagen.

Kruger, T., Davies, A. C., Eckersley, B., Newell, F., \& Cherednichenko, B. (2009). Effective and sustainable university-school partnerships: Beyond determined efforts by inspired individuals. Canberra, Australia: Australian Institute for Teaching and School Leadership Limited.

Lamb, P., \& Aldous, D. (2016). Exploring the relationship between reflexivity and reflective practice through lesson study within initial teacher education. International Journal for Lesson and Learning Studies, 5(2), 99-115. doi:doi:10.1108/IJLLS-11-2015-0040

Larssen, D. L. S., Cajkler, W., Mosvold, R., Bjuland, R., Helgevold, N., Fauskanger, J., . . . Norton, J. (2018). A literature review of lesson study in initial teacher education: Perspectives about learning and observation. International Journal for Lesson and Learning Studies, 7(1), 8-22.

Murphy, R., Weinhardt, F., Wyness, G., \& Rolfe, H. (2017). Lesson Study: Evaluation report and executive summary. Retrieved from London: https://educationendowmentfoundation.org.uk/public/files/Projects/Evaluatio $\underline{\text { n Reports/Lesson Study.pdf }}$

Star, S. L., \& Griesemer, J. R. (1989). Institutional ecology,translations' and boundary objects: Amateurs and professionals in Berkeley's Museum of Vertebrate Zoology, 1907-39. Social studies of science, 19(3), 387-420.

Takahashi, A., \& McDougal, T. (2016). Collaborative lesson research: maximizing the impact of lesson study. ZDM, 48(4), 513-526. doi:10.1007/s11858-015-0752-x

Toshiya, C., \& Toshiyuki, K. (2013). How Japanese schools build a professional learning community by lesson study. International Journal for Lesson and Learning Studies, 2(1), 12-25. doi:doi:10.1108/20468251311290105

Tsui, A. B., \& Law, D. Y. (2007). Learning as boundary-crossing in school-university partnership. Teaching and Teacher Education, 23(8), 1289-1301.

Wake, G., Swan, M., \& Foster, C. (2016). Professional learning through the collaborative design of problem-solving lessons. Journal of Mathematics Teacher Education, 19(2), 243-260.

Zeichner, K. (2010). Rethinking the connections between campus courses and field experiences in college-and university-based teacher education. Journal of Teacher Education, 61(1-2), 89-99. 